\title{
Pathogenesis of polymyalgia rheumatica
}

\author{
G. Guggino, A. Ferrante, F. Macaluso, G. Triolo, F. Ciccia \\ Biomedical Department of Internal Medicine, Division of Rheumatology, University of Palermo, Italy
}

\begin{abstract}
SUMMARY
Polymyalgia rheumatica (PMR) is a chronic, inflammatory disorder of unknown cause, almost exclusively occurring in people aged over 50 and often associated with giant cell arteritis. The evidence that PMR occurs almost exclusively in individuals aged over 50 may indicate that age-related immune alterations in genetically predisposed subjects contribute to development of the disease. Several infectious agents have been investigated as possible triggers of PMR even though the results are inconclusive. Activation of the innate and adaptive immune systems has been proved in PMR patients as demonstrated by the activation of dendritic cells and monocytes/macrophages and the altered balance between Th17 and Treg cells. Disturbed B cell distribution and function have been also demonstrated in PMR patients suggesting a pathogenesis more complex than previously imagined. In this review we will discuss the recent findings regarding the pathogenesis of PMR.
\end{abstract}

Key words: Polymyalgia rheumatica; Innate immunity; Adaptive immunity; Pathogenesis.

Reumatismo, 2018; 70 (1): 10-17

\section{INTRODUCTION}

Dolymyalgia rheumatica (PMR) is a chronic, inflammatory disorder of unknown cause almost exclusively occurring in people aged over 50 (1-3). PMR is clinically characterised by the acute or subacute onset of pain and stiffness in the neck, shoulders, hips, upper arms, and thighs $(3,4)$. A very strong association has been demonstrated between PMR and giant cell arteritis (GCA) (5-7), a systemic, granulomatous vasculitis mainly affecting the aorta and its branches (8). Although the pathogenesis of GCA has been extensively studied, the pathogenic mechanisms underlying PMR are less clearly defined. The evidence that PMR occurs almost exclusively in individuals aged over 50 years may indicate that, similarly to GCA, age-related immune alterations in genetically predisposed subjects contribute to the development of the disease $(9,10)$. In this review we will discuss recent findings regarding the pathogenesis of PMR (Figure 1).

\section{IMMUNOGENETICS}

Several studies have reported an association between the disorder and spe- cific polymorphisms in genes related to immune regulation. HLA class II histocompatibility antigen, DRB1 beta chain is a protein that is encoded in humans by the $H L A-D R B 1$ gene. Several alleles of DRB1 (shared epitope alleles) are associated with an increased incidence of joint inflammation as seen in rheumatoid arthritis (11).

The association between HLA-DRB1 genotypes and susceptibility to polymyalgia rheumatica is controversial. Unlike PMR associated with GCA, which is generally associated with HLA-DRB $1 * 04$ alleles, the HLA-DRB1 susceptibility to isolated PMR varies in different populations $(9,12)$. The association between HLA-DRB $1 * 04$ alleles and isolated PMR has been suggested by Salvarani et al., who reported a high incidence of HLADR1 among their Italian patients with isolated PMR (13). In addition, Gonzalez Gay et al. have suggested a possible influence of HLA-DRB $1 * 04$ alleles in the development of more severe disease with a more pronounced synovial inflammation in patients from the North-western Spain $(4,14)$. The inflammation of sub-acromial and sub-deltoid bursa in PMR patients 
suggests that cytokines involved in the inflammatory process may play a role in the pathogenesis of the disease. In this regard, PMR has been demonstrated to be associated with different TNF polymorphisms. Isolated PMR in patients from Lugo, North-western Spain, has been in fact positively associated with TNF-b3, independently of the HLA-class II association, and negatively associated with TNF-d4 (15). Beyond TNF区, the genetic contribution of other pro-inflammatory cytokines has been studied in PMR patients. The IL-1RN*2 allele, particularly when homozygous, is associated with increased susceptibility to PMR and the IL-6 promoter polymorphism is associated with biopsy-proven GCA patients with PMR manifestations in Italian patients $(16,17)$. The TLR9 Thr399Ile CC genotype has been associated with a higher cumulative dose of corticosteroids in Spanish patients with PMR $(18,19)$.

Genetic polymorphisms associated with PMR risk or severity in Italian patients include intercellular adhesion molecule 1, interleukin 1 receptor antagonist, and interleukin $6(16,17,20)$.

\section{INFECTIOUS AGENTS}

The hypothesis has long been considered that in a genetically predisposed patient, an environmental factor, possibly a virus, may induce monocyte and dendritic cell activation and the production of pro-inflammatory cytokines that induce manifestations characteristic of PMR (21, 22). However, although several infectious agents have been investigated as possible triggers, the results are inconclusive. The synchronous variations in the incidences of PMR recorded in Denmark strongly indicate that an environmental infectious factor may influence the frequency of the disease (23). In this regard, Elling et al. demonstrated a close concurrence with epidemics of $M$. pneumoniae and the coincidence of 2 epidemics of parvovirus B19 and of one epidemic of C. pneumoniae. Additionally, in studies from the UK and Italy, PMR occurred more often

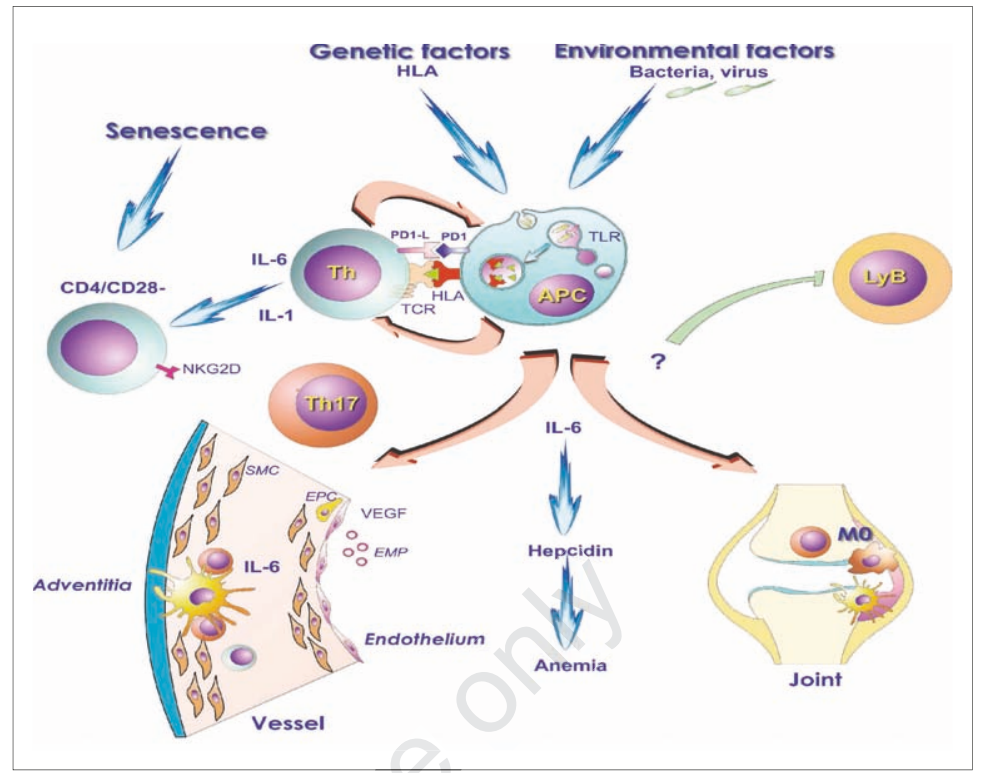

Figure 1 - Pathogenic mechanisms in polymyalgia rheumatica (PMR). Pathogenesis of PMR is thought to be the result of the interaction between environmental factors, possibly virus, and the innate immune system in genetically predisposed individuals. The senescence of the immune systems as demonstrated by the loss of the CD28 on CD4+ T senescent cells may be responsible for aberrant immune responses in PMR. Adaptive immune alterations also occurs in PMR mainly represented by the activation of Th17 cells, mainly driven by the increased IL-6 levels. An altered distribution and phenotype of B cells also occurs in PMR even in the absence of a clear autoimmune response. Local activation of myeloid and endothelial cells has been also demonstrated in the non-inflamed arteries and inflamed synovial tissues of PMR patients.

during summer months than during winter months (24). In a different cohort of patients, however, onset of PMR symptoms was unrelated to seasonal pattern with $50 \%$ of cases occurring in the months of May, February, and August. Cimmino et al. demonstrated that antibodies to adenovirus (ADV) and respiratory syncytial virus (RSV) were significantly more prevalent in PMR patients, suggesting that ADV and RSV might be the possible microorganisms responsible for triggering PMR in elderly people (24). Although a few studies reported the presence of an association between parvovirus B19 and PMR, the results have been not replicated in larger studies $(21,25)$. Finally, no role of current or previous hepatitis B virus infection has been demonstrated in the pathogenesis of the majority of cases of polymyalgia rheumatic (26). 


\section{INNATE IMMUNE RESPONSES}

Despite the evidence that PMR causes severe pain and stiffness in the proximal muscle groups, there is no evidence of inflammation in muscle biopsy and electromyographic findings are normal (27, 28). The inflammation in PMR patients has been demonstrated to occur at the level of the synovium and bursae associated with the shoulder and hip girdles, where the recognition of an unknown antigen by dendritic cells or macrophages occurs $(29,30)$. The synovitis of PMR is characterized by vascular proliferation and leukocyte infiltration, predominantly macrophages and T lymphocytes $(29,31)$. A few neutrophils, but no B cells, natural killer cells, or gamma/delta $\mathrm{T}$ cells have been found. Intense expression of HLA class II antigens (DR more than DP more than DQ) was found in the lining layer cells as well as in macrophages and lymphocytes. Class II antigen expression correlated with the number of macrophages and lymphocytes (30). In patients with PMR, adventitial DCs, even in the absence of vasculitic infiltrates, have been demonstrated to be mature and to produce CCL19 and CCL21. When PMR arteries are transplanted in SCID mice, DCs attract, retain, and activate $T$ cells that originated from the GCA lesions (32). Beyond the presence of activated macrophages in the synovial and arterial samples of PMR patients, a systemic activation of circulating monocytes has been also demonstrated, mainly characterized by the increased IL- 6 and IL-1 beta production (33).

Toll-like receptors (TLRs) are expressed on many types of cells including macrophages and dendritic cells (DCs) and play an essential role in the activation and regulation of innate immune responses through recognition of specific pathogenassociated molecular patterns and endogenous peptides (34). Increased expression of Toll-like receptor (TLR) 7 and TLR 9, which resolves with complete disease remission, has been demonstrated in the peripheral mononuclear blood cells of both PMR and GCA patients (18). However, al- lele and genotype and haplotype analysis of TLR9 T1486C and T1237C revealed no significant association with PMR susceptibility (19).

In the healthy immune system, aberrant immune stimulation is avoided by negative co-stimulatory signals that protect tissue tolerance. Programmed cell death protein 1, also known as PD-1 and CD279 (cluster of differentiation 279), is a cell surface receptor that plays an important role in the regulation of immune system homeostasis by suppressing $\mathrm{T}$ cell inflammatory activities (35). PD-1 acts by promoting apoptosis in antigen specific T-cells in lymph nodes while simultaneously reducing apoptosis in regulatory $\mathrm{T}$ cells (anti-inflammatory, suppressive $\mathrm{T}$ cells) (35). A recent study demonstrated that GCA-affected temporal arteries have low expression of the co-inhibitory ligand programmed death ligand-1 (PD-L1) concurrent with enrichment of the programmed death-1 (PD-1) receptor. In addition, tissue-residing and ex vivo-generated dendritic cells (DC) from GCA patients were PD-L1lo, whereas the majority of vasculitic T cells expressed PD-1, suggesting inefficiency of the immunoprotective PD-1/PD-L1 immune checkpoint (36). Although the expression of the PD1/PDL1 immune checkpoint has been never studied in PMR patients, several studies indicate the onset of PMR symptoms in patients treated with anti-PD1/anti-PDL-1 agents indicating a potential role of PD1/PDL1 signal in PMR pathogenesis $(37,38)$.

\section{ADAPTIVE IMMUNE RESPONSES}

Analysis of inflammatory cytokines expression in temporal artery tissues of GCA patients showed that in situ synthesis of interleukin-2 (IL-2), interferon-y (IFNy), and IL-1b mRNA, but not of IL-10 and IL-12 mRNA, distinguished different patterns of inflammation correlated with different clinical disease manifestations (39). Patients with evidence of ischemic symptoms, indicated by jaw claudication and/ or visual symptoms, typically expressed higher concentrations of IFNy mRNA and 
IL-1 $\beta$ mRNA (39). Presence of fever was correlated with lower copy numbers of IFNy. Formation of giant cells in the granulomatous infiltrates was associated with the local synthesis of IFNy mRNA (39). Tissue from GCA patients with concomitant PMR contained higher levels of IL-2 mRNA transcripts (39).

IL-6 is a cytokine displaying pleiotropic activity. IL-6 induces synthesis of acute phase proteins such as CRP, serum amyloid A, fibrinogen, and hepcidin in hepatocytes. IL-6 also plays an important role in acquired immune response by stimulation of antibody production and of effector Tcell development such as Th17 cells (40). Patients with PMR often show elevated IL6, IL-1Ra and BAFF levels closely related with clinical symptoms (41-45). Corticosteroids rapidly suppress IL-6 production but do not correct the underlying mechanism, inducing increased IL-6 production since short-term withdrawal of corticosteroids, even after several months of treatment, is followed by an immediate increase in plasma IL-6 concentrations (44). In addition, most studies in PMR show that a decrease in the level of circulating IL-6 correlates with remission of clinical symptoms and that high serum IL-6R levels combined with low haemoglobin values resulted in a ten-fold increased risk of PMR relapse (45). Boiardi et al. showed that the CC IL-6 genotype characterized PMR patients with persistently elevated levels of IL-6 who are at higher risk of developing relapse/recurrence (17). Altogether, these findings indicate that a genetically modulated pattern of IL-6 production could affect the long-term outcome of patients with PMR (17). Data on other circulating cytokines (e.g., IL-1, IL-2, TNF-alpha, IL-10) are too few to draw any conclusions.

According to the important role of IL-6 in modulating the function of effector Treg and Th17 cells, the disturbed IL- 6 production demonstrated in PMR should be associated with a disturbed effector T-cells distribution. Compared with control subjects, patients with PMR have a decreased frequency of Treg cells, whereas the percentage of Th17 cells was significantly increased and reduced by glucocorticoid treatment (46). Although the frequency of $\mathrm{CD} 161^{+} \mathrm{CD} 4^{+} \mathrm{T}$-cells, which are considered to be Th17 cell precursors, is similar in patients and control subjects, their ability to produce interleukin-17 in vitro is significantly enhanced in patients with PMR (46). Beyond the altered distribution of Treg/Th17 cells, Shimojima demonstrated a decrease in activated cytotoxic/suppressor T-cells and increases in circulating Th1 and Tc1 cells in PMR patients (47). A significant decrease in absolute numbers and relative percentages of $\mathrm{CD} 8+\mathrm{T}$ lymphocytes, inversely correlated with the acute hepatic phase reactants and modified by steroids treatment has been demonstrated in PMR patients (48-53). The studies performed by Martinez-Taboada and co-workers do not confirm, however, the previous findings that the proportion or number of circulating CD8+ T-cells are reduced in patients with active PMR (53). The Authors demonstrated that untreated PMR/GCA patients carried multiple clonally expanded CD8 populations. Molecular analysis of the $\mathrm{CD}^{+}$clonotypes showed a restricted TCR repertoire in the patients with a distinct Jbeta gene segment usage (54). Oligoclonality in the $\mathrm{CD} 8$ repertoire persisted despite successful control of the disease activity, suggesting that the $\mathrm{CD} 8+$ clonotypes are not an epiphenomenon of the inflammation (54). The same group demonstrated that the phenotype of circulating T-cells in patients with PMR/GCA is similar to that found in aged healthy subjects, except for the surface markers of naive and memory cells and a striking non-activated phenotype (55). In particular, Lopez-Hoyos and co-workers showed that specific TCR BV changes occur in patients with active disease accompanied by a significant decrease in certain TCRBV families in both CD4+ and CD8+ T-cell subsets, which may favour the participation of a superantigen stimulation in PMR/GCA (54). In both GCA and PMR patients, NKG2D was preferentially expressed on senescent CD4 CD28(-) and CD8 CD28(-), as well as on CD8 CD28 Tcells (55). Frequencies of senescent T-cells were increased in GCA and PMR patients 
compared to HC. In GCA tissue samples, infiltrating T-cells were predominately CD28(-).

NKG2D is a potent activating receptor expressed on virtually all NK cells, on most NKT cells and subpopulations of $\gamma \delta \mathrm{T}$ cells. All human CD8+ $\alpha \beta$ T-cells express NKG2D, whereas NKG2D expression on CD4+ $\alpha \beta$ T-cells has been reported only in pathological conditions (56). In both PMR patients, NKG2D is preferentially expressed on senescent CD4 CD28(-) and CD8 CD28(-), as well as on CD8 CD28 $\mathrm{T}$-cells and the frequencies of senescent $\mathrm{T}$ cells are increased in PMR patients. In the presence of antigenic stimulation, a rapid up-regulation of NKG2D on CD4 CD28() and CD4 CD28 T-cells is observed. Interestingly, TNF- $\alpha$ and interleukin-15 enhanced NKG2D expression on senescent CD4 and CD8 T-cells only. Finally, NKG2D cross-linkage augmented anti-CD3 triggered proliferation, IFN- $\gamma$ and TNF- $\alpha$ production of CD8 T-cells (31).

B-lymphocytes are crucial components of both innate and adaptive immunity. Although an autoimmune component has been never demonstrated in PMR patients, a decreased frequency of circulating $B$ cell has been demonstrated in PMR, rapidly recovered after steroid treatment (57). Interestingly, in PMR the B cell numbers are inversely correlated with erythrocyte sedimentation rates, C-reactive protein levels, and serum BAFF levels. In particular, the frequency of Tumour necrosis factor $\alpha$-positive Beff cells was decreased in patients newly diagnosed with PMR and normalized by steroid treatment (57). More recently, it has been demonstrated that B-cell lymphopenia and abnormal Bcell subset distribution, associated with disease activity and IL-6 concentration, are corrected by the IL- 6 antagonist tocilizumab (57).

\section{ENDOTHELIAL DYSFUNCTION IN POLYMYALGIA RHEUMATICA}

Systemic inflammation in many human diseases has been associated with an im- balance between endothelial injury and repair characterized by a reduced number of endothelial progenitor cells (EPCs) (58). Pirro and co-workers have recently studied the association between inflammation and endothelial injury and repair in patients with PMR (59).

The Authors demonstrated that PMR is associated with a significant imbalance between endothelial injury and repair, which is dependent on the degree of systemic inflammation.

In this study, levels of C-reactive protein (CRP) were associated with an increased circulating endothelial microparticles (EMP) EMP/EPC ratio, irrespective of traditional cardiovascular risk factors. Corticosteroid therapy led to a significant CRP reduction paralleled by a consistent decline in the EMP/EPC ratio (59). The occurrence of endothelial dysfunction in PMR is also suggested by the finding that VEGF serum concentrations are significantly higher in untreated PMR. PBMC isolated from untreated PMR patients spontaneously secrete a higher amount of VEGF compared with PBMC from control subjects and corticosteroid therapy does not affect the ability of PBMC to produce VEGF.

Immunohistochemical staining performed on shoulder synovial tissue showed VEGF expression in both the lining layer and the sublining area and was correlated with vessel density, but was not associated with alphavbeta3 and alphavbeta5 integrin express (60).

\section{CONCLUSIONS}

The pathogenesis of PMR appears to be more complex than previously thought. Activation of innate and adaptive immune systems in response to unknown environmental triggers appears to be the key pathogenetic mechanism in PMR. A role of B cells in modulating systemic immune responses in PMR appears to be also relevant. Further studies are required, however, to clarify better the cascade of events that lead to aberrant activation of the immune system in PMR. 


\section{REFERENCES}

1. Salvarani C, Cantini F, Boiardi L, Hunder GG. Polymyalgia rheumatica. Best Pract Res Clin Rheumatol. 2004; 18: 705-22.

2. Salvarani C, Boiardi L, Macchioni L, et al. Polymyalgia rheumatica. Lancet. 1996; 348: 550-1.

3. Salvarani C, Macchioni P, Boiardi L. Polymyalgia rheumatica. Lancet. 1997; 350: 43-7.

4. Gonzalez-Gay MA, Garcia-Porrua C, Salvarani $\mathrm{C}$, et al. Polymyalgia manifestations in different conditions mimicking polymyalgia rheumatica. Clin Exper Rheumatol. 2000; 18: 755-9.

5. Cimmino MA, Salvarani C. Polymyalgia rheumatica and giant cell arteritis. Bailliere's Clin Rheumatol. 1995; 9: 515-27.

6. Salvarani C, Cantini F, Boiardi L, Hunder GG. Polymyalgia rheumatica and giant-cell arteritis. N Engl J Med. 2002; 347: 261-71.

7. Salvarani C, Cantini F, Hunder GG. Polymyalgia rheumatica and giant-cell arteritis. Lancet. 2008; 372: 234-45.

8. Muratore F, Pazzola G, Pipitone N, et al. Large-vessel involvement in giant cell arteritis and polymyalgia rheumatica. Clin Exper Rheumatol. 2014; 32: S106-11.

9. Salvarani C, Macchioni P, Zizzi F, et al. Epidemiologic and immunogenetic aspects of polymyalgia rheumatica and giant cell arteritis in northern Italy. Arthrit Rheum. 1991; 34: 351-6.

10. Salvarani C, Rossi F, Macchioni P, et al. Synovitis in polymyalgia rheumatica: an immunogenetic study. Br J Rheumatol. 1992; 31: 720.

11. Kampstra ASB, Toes REM. HLA class II and rheumatoid arthritis: the bumpy road of revelation. Immunogenetics. 2017 [Epub ahead of print].

12. Salvarani C, Boiardi L, Mantovani V, et al. HLA-DRB1 alleles associated with polymyalgia rheumatica in northern Italy: correlation with disease severity. Annals Rheum Dis. 1999; 58: 303-8.

13. Salvarani C, Cantini F, Olivieri I. Distal musculoskeletal manifestations in polymyalgia rheumatica. Clin Exper Rheumatol. 2000; 18: S51-2.

14. Gonzalez-Gay MA, Garcia-Porrua C, Salvarani $\mathrm{C}$, et al. The spectrum of conditions mimicking polymyalgia rheumatica in Northwestern Spain. J Rheumatol. 2000; 27: 2179-84.

15. Mattey DL, Hajeer AH, Dababneh A, T et al. Association of giant cell arteritis and polymyalgia rheumatica with different tumor necrosis factor microsatellite polymorphisms. Arthrit Rheum. 2000; 43: 1749-55.

16. Boiardi L, Salvarani C, Timms JM, et al. Interleukin-1 cluster and tumor necrosis factoralpha gene polymorphisms in polymyalgia rheumatica. Clin Exper Rheum. 2000; 18: 675-81.

17. Boiardi L, Casali B, Farnetti E, et al. Relationship between interleukin 6 promoter polymorphism at position -174, IL-6 serum levels, and the risk of relapse/recurrence in polymyalgia rheumatica. J Rheumatol. 2006; 33: 703-8

18. Alvarez-Rodriguez L, Lopez-Hoyos M, Beares I, et al. Toll-like receptor 4 gene polymorphisms in polymyalgia rheumatica and elderly-onset rheumatoid arthritis. Clin Exper Rheumatol. 2011; 29: 795-800.

19. Alvarez-Rodriguez L, Lopez-Hoyos M, Beares I, et al. Toll-like receptor 9 gene polymorphisms in polymyalgia rheumatica and giant cell arteritis. Scand J Rheumatol. 2012; 41: 487-9.

20. Salvarani C, Casali B, Boiardi L, et al. Intercellular adhesion molecule 1 gene polymorphisms in polymyalgia rheumatica/giant cell arteritis: association with disease risk and severity. J Rheumatol. 2000; 27: 1215-21.

21. Drago F, Ciccarese G, Agnoletti AF, et al. Remitting seronegative symmetrical synovitis with pitting edema associated with parvovirus B19 infection: two new cases and review of the comorbidities. Int J Dermatol. 2015; 54: e389-93.

22. Iwata K, Mizuno Y. A case of polymyalgia rheumatica following influenza B infection. Int J General Med. 2015; 8: 345-7.

23. Elling P, Olsson AT, Elling H. [Synchronous variations in the incidence of temporal arteritis and polymyalgia rheumatica in Danish counties. Association with epidemics of Mycoplasma pneumonia infection]. Ugeskrift Laeger. 1997; 159: 4123-8.

24. Cimmino MA, Caporali R, Montecucco $\mathrm{CM}$, et al. A seasonal pattern in the onset of polymyalgia rheumatica. Annals Rheum Dis. 1990; 49: 521-3.

25. Peris P. Polymyalgia rheumatica is not seasonal in pattern and is unrelated to parvovirus b19 infection. J Rheumatol. 2003; 30: 2624-6.

26. Elling H, Skinhoj P, Elling P. Hepatitis B virus and polymyalgia rheumatica: a search for HBsAg, HBsAb, HBcAb, HBeAg, and HBeAb. Annals Rheum Dis. 1980; 39: 511-3.

27. Brooke MH, Kaplan H. Muscle pathology in rheumatoid arthritis, polymyalgia rheumatica, and polymyositis: a histochemical study. Archiv Pathol. 1972; 94: 101-18.

28. Gross MD, Borkin MH, Rupp S. Unusual electromyographic findings in a patient with polymyalgia rheumatica. Arthrit Rheum. 1979; 22: 277-80.

29. Dejaco C, Duftner C, Buttgereit F, et al. The spectrum of giant cell arteritis and polymyalgia rheumatica: revisiting the concept of the disease. Rheumatology. 2017; 56: 506-15. 
30. Meliconi R, Pulsatelli L, Uguccioni M, et al. Leukocyte infiltration in synovial tissue from the shoulder of patients with polymyalgia rheumatica. Quantitative analysis and influence of corticosteroid treatment. Arthrit Rheum. 1996; 39: 1199-207.

31. Dejaco C, Duftner C, Al-Massad J, et al. NKG2D stimulated T-cell autoreactivity in giant cell arteritis and polymyalgia rheumatica. Annals Rheum Dis. 2013; 72: 1852-9.

32. Ma-Krupa W, Jeon MS, Spoerl S, et al. Activation of arterial wall dendritic cells and breakdown of self-tolerance in giant cell arteritis. $\mathbf{J}$ Exper Med. 2004; 199: 173-83.

33. Wagner AD, Goronzy JJ, Weyand CM. Functional profile of tissue-infiltrating and circulating CD68+ cells in giant cell arteritis. Evidence for two components of the disease. J Clin Invest. 1994; 94: 1134-40.

34. Marshak-Rothstein A. Toll-like receptors in systemic autoimmune disease. Nat Rev Immunol. 2006; 6: 823-35.

35. Bardhan K, Anagnostou T, Boussiotis VA. The PD1:PD-L1/2 Pathway from discovery to clinical implementation. Front Immunol. 2016; 7: 550.

36. Zhang H, Watanabe R, Berry GJ, et al. Immunoinhibitory checkpoint deficiency in medium and large vessel vasculitis. Proc Natl Acad Sci U S A. 2017; 114: E970-9.

37. Le Burel S, Champiat S, Mateus C, et al. Prevalence of immune-related systemic adverse events in patients treated with anti-Programmed cell Death 1/anti-Programmed cell Death-Ligand 1 agents: A single-centre pharmacovigilance database analysis. Eur J Cancer. 2017; 82: 34-44.

38. Abdel-Wahab N, Shah M, Suarez-Almazor ME. Adverse events associated with immune checkpoint blockade in patients with cancer: a systematic review of case reports. PLoS One. 2016; 11: e0160221.

39. Weyand CM, Tetzlaff N, Björnsson J, et al. Disease patterns and tissue cytokine profiles in giant cell arteritis. Arthritis Rheum. 1997; 40: $19-26$.

39. Schinnerling K, Aguillon JC, Catalan D, Soto L. The role of interleukin-6 signalling and its therapeutic blockage in skewing the T cell balance in rheumatoid arthritis. Clin Exper Immunol. 2017; 189: 12-20.

40. Roche NE, Fulbright JW, Wagner AD, et al. Correlation of interleukin-6 production and disease activity in polymyalgia rheumatica and giant cell arteritis. Arthrit Rheum. 1993; 36: 1286-94.

41. Uddhammar A, Sundqvist KG, Ellis B, Rantapaa-Dahlqvist S. Cytokines and adhesion molecules in patients with polymyalgia rheumatica. Br J Rheumatol. 1998; 37: 766-9.

42. Cutolo M, Montecucco CM, Cavagna L, et al. Serum cytokines and steroidal hormones in polymyalgia rheumatica and elderly-onset rheumatoid arthritis. Annals Rheum Dis. 2006; 65: 1438-43.

43. Alvarez-Rodriguez L, Lopez-Hoyos M, Mata $\mathrm{C}$, et al. Circulating cytokines in active polymyalgia rheumatica. Annals Rheum Dis. 2010; 69: 263-9.

44. van der Geest KS, Abdulahad WH, Rutgers A, et al. Serum markers associated with disease activity in giant cell arteritis and polymyalgia rheumatica. Rheumatology. 2015; 54: 1397-402.

45. Pulsatelli L, Boiardi L, Pignotti E, et al. Serum interleukin-6 receptor in polymyalgia rheumatica: a potential marker of relapse/ recurrence risk. Arthrit Rheum. 2008; 59: 1147-54.

46. Samson M, Audia S, Fraszczak J, et al. Th1 and Th17 lymphocytes expressing CD161 are implicated in giant cell arteritis and polymyalgia rheumatica pathogenesis. Arthrit Rheum. 2012; 64: 3788-98.

47. Shimojima Y, Matsuda M, Ishii W, et al. Analysis of peripheral blood lymphocytes using flow cytometry in polymyalgia rheumatica, RS3PE and early rheumatoid arthritis. Clin Exper Rheumatol. 2008; 26: 1079-82.

48. Dasgupta B, Duke O, Timms AM, et al. Selective depletion and activation of CD8+ lymphocytes from peripheral blood of patients with polymyalgia rheumatica and giant cell arteritis. Annals Rheum Dis. 1989; 48: 307-11.

49. Elling H, Elling P, Olsson A. CD8+ lymphocyte subset in polymyalgia rheumatica and arteritis temporalis. Inverse relationship between the acute hepatic phase reactants and the CD8+ T-cell subset. Clin Exper Rheumatol. 1989; 7: 627-30.

50. Macchioni P, Boiardi L, Meliconi R, et al. Elevated soluble intercellular adhesion molecule 1 in the serum of patients with polymyalgia rheumatica: influence of steroid treatment. J Rheumatol. 1994; 21: 1860-4.

51. Arnold MH, Corrigall VM, Pitzalis C, Panayi GS. The sensitivity and specificity of reduced CD8 lymphocyte levels in the diagnosis of polymyalgia rheumatica/giant cell arteritis. Clin Exper Rheumatol. 1993; 11: 629-34.

52. Martinez-Taboada VM, Blanco R, Fito C, et al. Circulating CD8+ $\mathrm{T}$ cells in polymyalgia rheumatica and giant cell arteritis: a review. Semin Arthrit Rheum. 2001; 30: 257-71.

53. Martinez-Taboada VM, Goronzy JJ, Weyand CM. Clonally expanded CD8 T cells in patients with polymyalgia rheumatica and giant cell arteritis. Clin Immunol Immunopathol. 1996; 79: 263-70.

54. Lopez-Hoyos M, Bartolome-Pacheco MJ, Blanco R, et al. Selective T cell receptor decrease in peripheral blood $\mathrm{T}$ lymphocytes of 
patients with polymyalgia rheumatica and giant cell arteritis. Annals Rheum Dis. 2004; 63: 54-60.

55. Zafirova B, Wensveen FM, Gulin M, Polic B. Regulation of immune cell function and differentiation by the NKG2D receptor. Cell Mol Life Sci CMLS. 2011; 68: 3519-29.

56. Carvajal Alegria G, Devauchelle-Pensec V, Renaudineau Y, et al. Correction of abnormal B-cell subset distribution by interleukin-6 receptor blockade in polymyalgia rheumatica. Rheumatology. 2017 [Epub ahead of print].

57. Van der Geest KS, Abdulahad WH, Chalan P, et al. Disturbed B cell homeostasis in newly diagnosed giant cell arteritis and polymyal- gia rheumatica. Arthrit Rheum. 2014; 66: 1927-38.

58. Ferrante A, Guggino G, Di Liberto D, et al. Endothelial progenitor cells: Are they displaying a function in autoimmune disorders? Mech Ageing Dev. 2016; 159: 44-8.

59 Pirro M, Bocci EB, Di Filippo F, et al. Imbalance between endothelial injury and repair in patients with polymyalgia rheumatica: improvement with corticosteroid treatment. J Intern Med. 2012; 272: 177-84.

60. Meliconi R, Pulsatelli L, Dolzani P, et al. Vascular endothelial growth factor production in polymyalgia rheumatica. Arthrit Rheum. 2000; 43: 2472-80. 